\title{
CITIZEN SCIENCE IMPLICATIONS OF PUBLIC ACCESS TO 3-D HYPERMEDIA EDITING AND INTERACTIVITY IN THE HOME
}

\author{
Consumers as researchers - Homes as laboratories
}

\author{
Kresten Bjerg \\ Retired Associate Professor, Insitute forPsychology, University of Copenhagen, Denmark.
}

Key words: Accountability, Home, Body, Neighbourhood, Citizen Science, Multimedia, 3-D, Protocol level, Time-perspective, Home-to-home, Multi-cultural, Epistemology, Referential description, Icons, Unicode standard, Cortical hemispheres, Tobacco, Health-policies, Homelink, Virtual Reality, Social field theory.

\begin{abstract}
This paper outlines a pattern to connect (1) our present understanding of the cultural home and the ethnic household as an ongoing process of situated and sedimented managed action and exchange of all kinds with (2) a new understanding of the challenges inherent in the introduction of front-line information technology to the multimedia-home. It defends the position, that democratic long-term citizen interests make it necessary to look at homes in an "oikocentric" (homecentered) perspective, in contrast to, and in dialog with, the dominant marketing science perspectives. A synthesis is suggested of the potentials of 3-D editing and linking, where home, body and time are seen as linkable representational spheres, and where users' own symbols of typicalities can be annotationally represented in temporal depth-perspectives. This is theoretically linked to conceptions of a new ontology and a new epistemology based on a distinction of sensorial and choice-categories. Finally the themes of virtual homes and virtual neighbourhoods, citizens as researchers and homes as studies, studios and laboratories are related to the grounding of broadband communication between homes.
\end{abstract}

The original version of this chapter was revised: The copyright line was incorrect. This has been corrected. The Erratum to this chapter is available at DOI: 10.1007/978-0-387-35511-5_17 


\section{INTRODUCTION}

In this presentation I will outline broader backgrounds and perspectives of the enterprise of this conference and book, hoping to point out directions of relevance to the future of grounded, shareable citizen science.

The subject of our research: the private home(life) and its electronics, is in the eye of the information technology cyclone. But, rather than being intimidated by all this new technology, one may instead focus on the home as the inevitable key to, and crib of, the new. This way one can begin identifying the dimensions of potential empowerment through a new citizen e-literacy.

I have, since 1980 been bent on identifying long-term user-, consumerand citizen-interests in Domestic Information, Communication and Automation Technology, and I will explain the set of conclusions which I have reached. I will address the frustration accumulating in citizens as the literacies necessary to act informed and critically are multiplying, while the adequacy and availability of relevant tools to deal practically with the informative abundance of the live domestic information ecology is still severely restricted. The information overload is increasing while our tools for handling the information don't show much progress.

Three main premises of the approach are that

1. one can consider the household/family in its local cultural specificity, as

an ongoing process of situated and sedimented managed activities and exchanges.

2. one can consider the habitant as situated within an "oikosphere" of informative objects, distributed in space and time

3. one can consider the inhabitant as well as the "oikosphere" as objects in time, giving a dynamical domestic information ecology.

These premises contain the major conceptual reference-points necessary for an informed discussion of the challenges inherent in the introduction of communication technology to the multimedia-home, if this technology is to be in the long-term interest of the democratic citizen.

\section{OIKOCENTRIC VS. MARKETING SCIENCE PERSPECTIVES}

The traditional cultural domestic information-ecology is seriously threatened with the media-bombardment and multimedia in the home, a

1 Oikos is Greek, means home and household, and is the source of the words Economy (oikonomia) and Ecology (Oikologia) 
threat of cultural discontinuity, disempowerment in regard to accountability ${ }^{2}$ and ensuing mental isolation. The self-feeling and sense of coherent identity of the citizen is threatened because one's self is evolving and defined by the sharing relation to other people's evolving selves, and such relations are endangered or severed when the communication is solitary, unshareable, one-way or (semi-)anonymous[23].

Therefore honest regard for democratic long-term citizen interests makes it necessary to look at homes in an oikocentric (home-centred) perspective, in contrast to the marketing science perspective so dominant in present ICT $^{3}$ policies, in explorative $\&$ exploitative endeavours.

At our last conference, HOIT94 [10], before the reverberatory impact of the World Wide Web, this viewpoint had to sound naively idealistic because the marketing science perspective was indispensable to boost the development of the internet and its related software. None of us can disregard the marketing science perspective. Our demands of future ICT in the private homes of citizens is of course in a dependency-relation to growth and development of commercial services. However, after witnessing the takeoff of the WWW, one can now consider it generally profitable and thus "sustainable", particularly in the light of growing political agreement about the economic (and perhaps even democratic) desirability of common domestic access and everyday use of (two-way? ? $^{4}$ broadband to the home. Therefore: The time has come to turn the table of the game:

$\mathrm{We}$, and the responsible research authorities, must now prioritise the oikocentric perspective if we shall make a qualified contribution to longterm citizen interests.

\section{THE OIKOCENTRIC PERSPECTIVE}

The Oikocentric Perspective means grounding in the local: The particular home, the particular neighbourhood. Not as an abstract place, seen objectively and quantitatively from above and the outside, but rather seen as a concrete scene and arena, objectively and subjectively from the inside, qualitatively process-wise describable.

Research into the oikocentric perspective has before been much more difficult to deal with systematically than it is going to be for two reasons:

1. The growing understanding and development of qualitative research methods[55] and

2 I owe the notion of accountability running through this paper to Harold Garfinkel[20]

3 Information and Communication Technology

4 Admittedly wishful thinking and just an expression of the author's hopes. 
2. The indisputable quantum leap of representational power inherent in recent multimedia tools and domestically applicable 3-D technologies [25], [26].

Thus the time has come to discuss the implications of public access to 3-D hypermedia editing in the home as regards:

- our understanding of the proximal zone of development of domestic information ecology,

- conceptual construction of the critical citizen and the multimedia-home,

- cultural continuity

- creation of a convivial bridge-building multi-ethnic community

- empowerment of democratic qualified expressability, and

- personal self-accountability

\section{DEALING WITH THE INDESCRIBABLE}

As earlier stated, the literacies necessary to act informed and critically are multiplying. By this I refer to the fact that tools for handling new types and copious amounts of information present in the domestic information ecology are severely inadequate. But I also refer to knowledge of new classes, families and languages of "letters" and keys, organised around the handling of information, in panels, menus, screens and keyboards. In brief: operating systems and separate software-programs, each powerful for its part of what would be needed for the purposes we are looking for.

The adequacy and availability of relevant tools to deal practically with the springs, the wells and wealth of informative abundance of live contemporary domestic information ecology is still very limited.

Not only are transactions so complex that we as users become involved in sequences of uncomfortable transactions of delays, detours, queuing, mis-spellings, copyright, stalling, retroactive obsolescence, tolls and subscriptions, expiring licenses, asyncronicities, incompatibilities, breakdown or insufficiency of extremely promising machinery, software, tele-companies and public and private service-providers But the relevant contexts as well as these transactions themselves are also so difficult to describe that we as users, consumers and citizens are unable to coherently designate the various levels and dependencies of our breakdowns. This means that the citizen is left with poor means to identify remedially relevant resources, to recognise, when help might be within reach - and to spot, when he has been cheated, outwitted or exploited.

I think the reader will agree with me that these hardships and informative overloads to a very large extent are experienced individually, without any 
witness other than you yourself and your computer-and perhaps your tele-provider.

It is with this "too complex to describe and too specific to interest even your closest mate" that the person is in a peculiar Catch-22 or "double-bind".

One aspect is being unable to relate and share individual problems and sources of stress with other household-members and beyond, but an even worse situation is that the person cannot even reflect upon the dynamic choices, events and barriers he/she has to deal with in a fluent present. They are so unproportionally difficult and all too time-consuming to take note of, to depict and visualize. Therefore they can only under considerable strain and memory-load be even fragmentarily reconstructed and used as "learned from time-geographically contextualised experience". However, tools to do precisely this, is what the public access to 3-D hypermedia editing in the home could provide.

History and culture have had their evolution, each stage building on the constructions of the previous evolution of languages and tools, worldmaking over previous world-makings[22]. Major shifts in paradigms and power structures have accompanied the introduction of new tools, enabling new actors to unfold inventive bricolage, unprecedented appropriations of accumulated knowledge and re-cultivation of the sedimented cultural soil[35]. Therefore it may not necessarily be naive to envisage, that a new age of enlightenment, specifically: a time-perspectival renaissance, shall result from the generative explosion of ICT tools. It is my hope that 3-D hypermedia editing in the home can be brought to empower the citizen precisely because it is in the unfolding scene of the private home that citizens are empowered.

However, we will get nowhere before a firm theoretical base is envisioned. We have got to amass a coherent terminology for a sufficient multi-dimensionality of the reflection around the task.

\section{PRINCIPIA DOMESTICA}

Let me outline the emerging concepts of a Theory of Domestic Information-Ecology. It is my assertion, that this theory conceptualises promising trails towards the emergence of appropriate tools for domestic self-accountability embedded in a self re-establishing cultural continuity. I

5 An elaborate structured exposition of this theory in Danish is available on the World Wide Web [9] 
wish it to be a tool to conceptualise, analyse and exemplify long term consumer-interests ${ }^{6}$ as regards information-technology to the home.

The theory doesn't presume that inhabitants are using modern ICT, but at the same time it is fit to use in exploring and conceptualising the uses one might want to have, not only of presently available services, but also of those, which theoretically can be developed. In this it is necessary to look at homes in an oikocentric perspective, in contrast to the marketing science perspective so dominant in present ICT-policies.

An oikocentric theory takes its issue in the existence of homes, inhabited by people, acting and communicating with themselves and each other, as well as with outsiders and actors such as TVs, telephones, computers, pens \& paper, watches etc.

A consequential aspect of this theory is that it maintains that the domestic information ecology constitutes the proto-platform for personal expression and reflection. This implies that extra-domestic, semi-public and public place, offices, schoolrooms, workshops and studios, (as well as international conferences like this) must be seen as secondary to the familiar domestic protoplatform.

\section{HOW CAN A CITIZEN FIND HER/HIS PROPER VOICE??}

Trying to take ICT policy and research in a direction less focused on commercial satisfaction and more on giving citizens a medium for expressing themselves, one must support the delivery of messages. Before considering who one is going to address (it might be oneself tomorrow, a friend, ones grandchildren, a politician) and before going into "about what" one must take note of the origin of the message, as an extremely identifiable pre-given time geographical particularity.

A majority of citizens are most repeatedly situated in their own nuclear domestic embedding platform. In other relevant platforms, such as offices, class-rooms, studios or coffee-bars ones expressability is severely constrained due to pre-supposed tasks and behaviours, thus ones genuine voice may easily fail., if it cannot stay harmonic with a domestic "proprietary" voice. Each platform is in principle embedded territorially in

6 Seen from a broad range of viewpoints: psychological, humanistic, sociological, culturalhistoric, health-political and ecological

7 I am here not referring specifically to voice communication, but to "proper voice" in the sense of Wertsch [59] 
its wider material and social environment and historically in a biography and multiples of biographies.

In her/his proper home the subject (the thinker, speaker, writer, actor, author, agent) is symbiotically rooted and anchored in a present life-world of distributed others and distributed informative objects, situated in a relative familiarity.

The crux of the matter then is, that when the platform of expression and reflection is the home, there exists a complex multitude of rooting structure there: the whole interior design and decoration and its changing arrangement of containers and displays.

The Civilised Home is a particular, personal and cultural stage-set of symbolic informative objects which to a large extent helps the individual define his self, and which continually offers the eyes and ears of the inhabitants a symphony of resonances [13], [36].

At home we can be grounded in the relatively stable proximal cultural inter-space and interface of our own information-household theatre (with its front-stages and back-stages around the clock) in the, ideally convivial, information ecology of precisely these inhabited rooms. Assertions on the "connection between time and space being suspended in post modern life" cannot apply to the resident population of household members. Instead we might agree in statements like "For the wealth of information there are only those shelves, which oneself can put up" and "Survival depends on learning how best to sort".

Now, not only the mind itself, but also the inhabited home is a sorted and sorting system web. Within it unfolds the dynamics of construing and construct-relating ${ }^{8}$ in:

a) attachments (personal and object relations) and

b) arrangements (Einrichtung) of informative objects in the home of origin

and in subsequent personal homemaking.

The organisation of a home can thus be seen as options and constraints for selecting, exchanging, playing, orienting and identifying uses and affections of persons and informative objects.

\section{OIKOSPHERE, SOMASPHERE, CHRONOSPHERE}

This then leads to the prediction that a fourth premise on which a theory of domestic information ecology must rest will be:

8 from the crib, involving and evolving, choice-dimensionalising, world-making and lifespace expanding 
4. The basic structures of familiar perceptual categories and choice categories ${ }^{9}$ are territorially and temporally distributed in the 3D spaces of the home and the bodies.

A "topoanalysis", as suggested by the French philosopher Gaston Bachelard [2] can reveal and contain a lot more meaning than even an object-relation-oriented psychoanalysis, which it may eventually come to subsume. We must introduce the home in the episteme, if we shall fully savour the implications of a realist ${ }^{10}$ re-interpretation of Kant's a priori transcendent categories, which here find their ecological material substrate, from the crib up. Now, this Oikosphere is one ontological and epistemological 3D space, whether we give it adequate tools of 3D representation or not.

But we have to separate a second 3D space: The Somasphere. The space of the body of the inhabitant in the habitat. It is time to follow up on the conclusive and consequential introduction of the body in the episteme by Willhelm Reich, Maurice Merleau-Ponty [40] and the further analyses of the body in language by Lakoff [32], Johnson [27] and others.

The body must be understood as a highly symbolic anatomic and physiological territory, forming a mobile state-varied continuum of reference, integrated in what Ulric Neisser[45] has aptly termed: the ecological self. Thus, a fifth premise of the foundation of a theory of domestic information ecology will include the Somasphere.

5. Epistemologically we must think of Oikosphere and Somasphere as revealed through different prisms, while together constituting a complementarity built into a non-algorithmic numeric category: the particular household in moments and periods of life, in various types of typicalities.

Seen in this light, Vygotskys promise: "Those, who could solve the enigma about the cell of psychology would find a key to the whole of psychology" [58] seems to have found its answer: Today, with a more mature ecological ontology than possible at Vygotskys time, this cell must be the living cell of the inhabited home.

9 This important distinction, close to the distinction of projectables and nonprojectables [18], [17] is crucial in the ecological realist reorientation in Danish anthropological psychology [38]

10 I am alluding here to the notions of "internal realism" [48], to the anti-rationalistic, existential and ecological turn of Heidegger [24] and Gibson [21] and to the convergence of such viewpoint with the concepts of the cultural-historic activity-theory of Vygotsky [12] and Leontjev [34] advanced by Mammen [39], and extended into the discriminated spheres of "pocketing" of Environment, Ecology and Habitat by Engelsted [16] with their materialist, non-dualist stress on the narrower and broader contexts of activity and communication. 
Fixating both the body and the home into the core of the episteme and of the ontology of humans constitutes a radical shift in our basis, central to our attempts of empowerment of citizens. Through this we can envision empowerment of representation crossing the bridges between the perceptually and the selectively categorized.

Finally, both somasphere and oikosphere are only understood through their evolution, through their dynamics. Thus time enters the stage as a prerequisite for a meaningful interpretation of self and surroundings

The two, now in principle veridically representable, universes: somasphere and oikosphere, can be conceived as joined by a third potential three-dimensionality: the Chronosphere.

The question of representation of the chronosphere is rather interesting as it has been depicted as linear time or as circular time, depending on the culture describing it. We visualize time both in narrow and higher resolution, from seconds, minutes, hours and days, to weeks, months, years, lifetimes, generations and up. It is important to note, to which extent such representation in the previous and present cultural history has been and still is limited to the flat 2-D media at disposal.

However, with the advent of easy access to 3-D representations, one can think of different descriptions of time, most obviously, of a merging description of linear and circular time. ${ }^{11}$ Depiction of linear temporal depth, e.g. months, years and lifetimes can be integrated with depiction of circular polarities like days, weeks, months etc. We can today safely predict that coherent algorithmically identifiable topologies of the 3-D Chronosphere will soon be possible, as shareware calendaric systems. However, to envisage the adaptation of such different calendaric systems to practical use, you will have to stretch your imagination .

Contrary to the Somasphere and Oikosphere, the Chronosphere is, in regard to personal and domestic life-processes, an essentially empty mathematical structure, although important culturally and socially structured in formats of weekday names, numbered weeks, named months and holidays and numbered years.

Of course the time-points and periods can be used as indexes and experiential log-point and reference point for past, occurring and anticipated events and states in both Somasphere and Oikosphere, but this does not in itself make a 3-D Chronosphere representation informative.

Writing words, or even scenes/images from Oikosphere or Somasphere into such a 3-D calendar may be adequate for certain purposes, but because

11 inherent already in the successive displacements of spots and areas of the surface of the rotating globe Terra, tracing trajectories of spirals of spirals in their relative and absolute physical galactic displacement 
of the limited amount of visual information that one can consume at a time, it imposes a near-sightedness defeating the utilization of 3-D for timeperspectival synthesis.

We have however a possibility of using 3-D chronospace as a medium for representation of loci, states, intentionalities and events in the two other 3-D spheres. And this has important implications for the elevation of the theory of domestic information ecology from art to science (our sixth premise):

6. By introducing the use of freely developed and freely size-variable icons for user-relevant typicalities of situations, acts, states and events, including cognitive events, linking between points and areas in one or both Oikosphere and Somasphere, a non-reductionistic, non-preemptory basic tool of practical reflexivity and self-accountability can be constructed, a tool which may point the way towards the longed for reconciliation between common sense "Grandma-psychology" [19] and Scientific Psychology.

Its potential for building bridges applies not only between sensorial categories and choice-categories, but also between the letters and the pictures, and consequently between the specialized left and right cerebral hemisphere. Approaching a clearer understanding of where this can bring us let us go back to the subjects "Choice of Voice", and relate it to the subjects relative liberty (autonomy) to organise and redistribute his/her available informative resources. Which voice to take depends on, which info-resources are within reach.

I propose, that these new techniques shall be considered from the vantage point of how they can be actively used by the lay citizens to express, describe and cope confidently and on their own cultural premises with the chaotic complexities of the information society, as these complexities tend to implode in the home.

\section{LEAP IN REPRESENTATIONAL POWER}

We have seen a great leap in the graphical abilities of ICT in the home. However, we still await a similar leap in representational power. I think it is critical to use these new 3D capabilities to break out of the restricting and fragmenting two-dimensionality of drawing space.

Thus one should pursue:

- civilising the techniques of constructing navigable annotatable picture rooms 
- civilising the "hyperlink" technique of establishing links of reference between single pages or even single words in text and to and from places, objects and times in picture-rooms.

- civilising the techniques of creating and animating humanlike electronic dolls and moving them in picture-rooms ${ }^{12}$

All of this must come together in a very special way, when directed toward the representation of our own proximal life-space. In this, concepts of homes as self-descriptive, self-referential systems and concepts of virtual homes and virtual neighbourhoods point a way to establish a grounding in real homes and real neighbourhoods for a technology otherwise risking to head us towards a devastating uprooting of persons from the most necessary local, biographical and cultural continuity.

\section{ANCHORING DOMESTIC INFORMATION ECOLOGY}

Households are more than ever in need of a frame of reference dimensions and directions, from which to count their existential origins. A nucleus of basic orientational coordinates. The home once had this role, but it tends to lose it. It is my hope that the private home of citizens can be reinstated as a life-raft with compass and gyroscope, with the help of which a sense of purposeful navigation through life can be maintained and developed, without purposes being planted from the outside.

We can, at least in a European perspective, think of the household and personal everyday life and socialisation in our own home as the most reliable foothold and first perspective necessary, when we look for such "a nucleus of basic co-ordinates, dimensions and directions" which can be tested to be trustworthy. The best frame of reference for an autonomous domestic information ecology is one, which is safely rooted in and modelled on the vessel of the home. An already structured aggregate of inhabited functional rooms and spaces, with a wealth of coherently and pragmatically distributed tools and associative informative objects.

Representing/mapping the individual oikosphere opens the access to a "virtual mirror of the home/doll-theatre-stage" as a coherent unmarked contextualising background for any kind of expression and reflective annotation from the actor's perspective, be it literal or figurative. A means for each household to embed its own cultural heritage and self-sedimented Intelligent Information Interfaces (i3)) and the computer game "The Sims" by Maxi are pointing the way. 
hyperspace of accumulated knowledge, expectations, commitments, values and valuables.

Representing/ mapping the individual somasphere opens likewise the access to a "virtual mirror of the body" as a coherent unmarked contextualising background for any kind of expression and reflective annotation from the actor's perspective, be it literal or figurative.

That such a pictorial matrix also offers means of detailed sedimented representation (visualisation and resounding) of bodily states and functions may open a new trail of health-related citizen science, and with it new inventiveness in the area of bio-telemetry

Such tools of orientation - taking the form of a home-made $3 \times 3-D$ computer interface - may be the only resilient, rational and realistic alternative to a multitude of non-transparent expert systems, systems for selfmanagement, medical expert systems, mind-body multimedia work-out programs etc. to be offered the ICT e-consumers through the state and commercial www-portals.

\subsection{Merging means of multidimensional orientation and the "Virtual Home"}

We are witnessing the merging of previously separate expressive cultures: The verbal cultures, the writing and paint-cultures, the newspaper, journal and book print cultures, the music-cultures, the dramatic and choreographic cultures, the TV-culture, the toy-cultures: Lego, doll-theatre, comic strips, animated movies. They can now all converge with, and within, the basic nuclear domestic culture. This may gradually empower the citizens to step into the role as effective producers of their own narrative to themselves, amongst themselves, to their contemporaries and to a possible future:

The merging of these media into one, integrated domestic multi-medium is not a question of replacing the old, separated expressive and impressive cultures, but sooner that of tying them together, adding a superior synthesising time-perspectival level of transforming, annotating and editing, storage and retrieval potential, across the media, integrating the means of relocating thematic contents of actualised local relevance within a consistent local and biographical time-geography.

We must demand, that future domestic multimedia systems should be construed and constructed with an a priori regard for their vital functions for coherent and sustainable personal attachments, orientation and identification, and also that they should be open-ended enough to adapt to the user, rather than vice versa. 
In short, this can best be accomplished through a domestic re-embedding of privately relevant information and information flows within a new kind of self-referential representational framework, a home-made multidimensional hyper-media mapping of the individual homes, in the uniqueness of their particular interior layout, furnishings and whole cultural symbolic interior surface and storage spaces.

I have, hesitantly ${ }^{13}$, suggested the notion of "Virtual Homes" as a designation for such frameworks, and the notion of "Virtual Neighborhood" for the possible corresponding mapping of more widely shared proximal surroundings. The Virtual Home will in principle be embeddable in the Virtual Neighbourhood, but its privileged autonomy and control of privacy can technically be maintained. In addition, the Virtual Neighbourhood, the Virtual Body and the virtual Temporal Manifold will, in principle, be embeddable in the Virtual Home

\section{DOMESTIC SPACE RESEARCH AND "HOMELINK"}

I think this can be used as a paradigm for an enculturable tool for users' autonomous existential orientation and life-space navigation from a selfbiographic home-centred ("oikocentric") perspective of privately and personally organised relevance-structures [49].

This should help reinstate the household members as masters of their shared and individual, inherited and acquired information resources. And it should enable their tying together, in a coherent conceptual pattern, the use of the entire domestic aggregate of cultural inheritance and tools, including electronic tools, in mutual sharing with chosen other households and homes, in the emerging "Homelink" architectures [53].

There is no doubt about the fact, that intrusion of new media in the homes - and especially the broadband linking of home to home - will afford the home a new central role in society, a changed role in production and an entirely new role in the development of knowledge [8]. In this, we will increasingly meet the new and the unknown in our own and parent homes. We will be exposed to new orders of information-complexity and overload, not least in visual and auditory information. And we will have practically unlimited cheap storage and retrieval capacities, for which there is no established culture or tradition. Therefore the citizens must come to see 
themselves as communicating researchers, a role which fits well with the notion of "critical consumers".

These are some of the arguments in favour of the development of tools for a new citizen science with its own new ideographic qualitative research methods in what we might call: "Domestic Space Research". While grounding in the particular domestic life-space and its processes it should hopefully contribute to critical and constructive dealing with the psychological, social and cultural aspects of reaching from one private sphere to another, from one home to another, from the home to the neighbourhood and to the wider society.

It is essential, that such oikocentric research must be performed by individual resident researchers or households and let its research interests be directed towards issues of personal relevance. However, it should point the way towards communities of citizens as autonomous, yet collaborating researchers, geared to socially responsible practical reflection.

File Edit 60 Toots Objects Font Style Elementer Ikoner Speciel Rapport $O()$

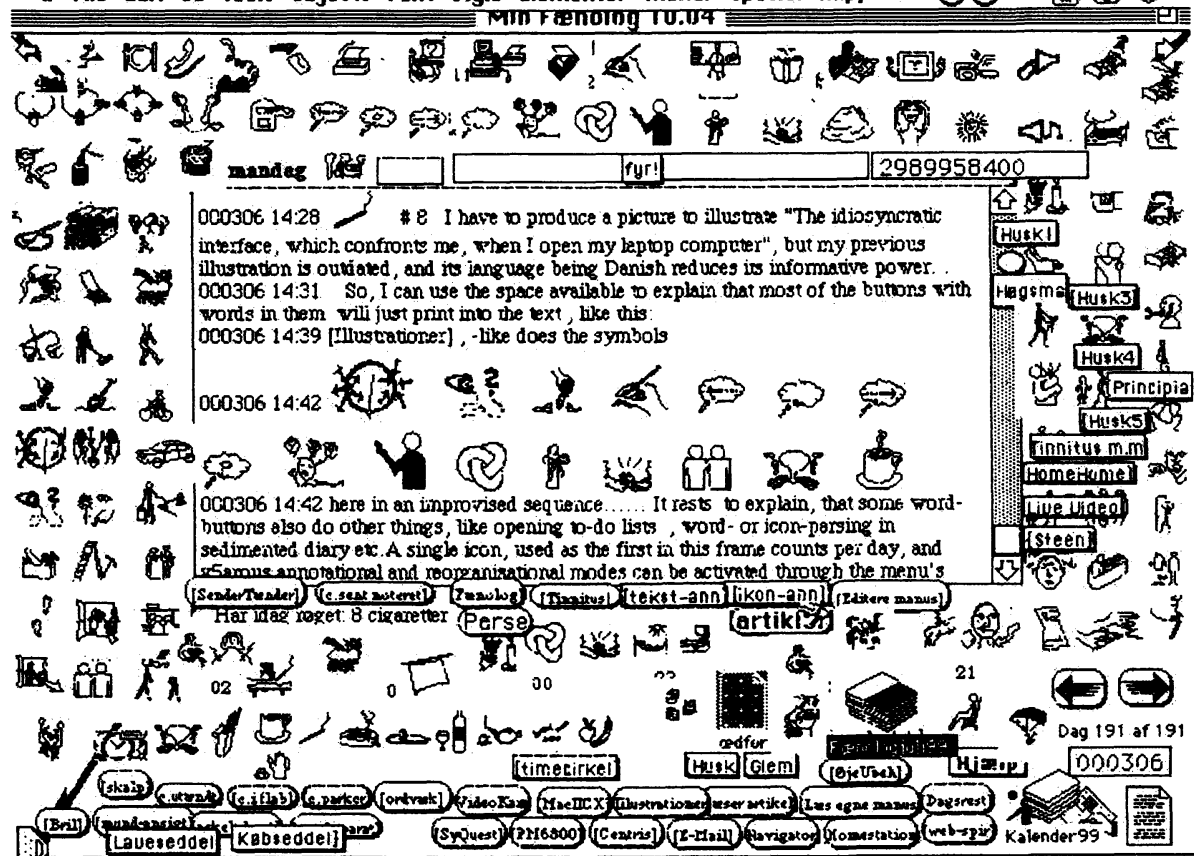

Figure 1. Idiosyncratic interface, which confront me, when I open my laptop-computer 


\section{THE POWER OF LOGGING}

One of my own approaches to the development of tools for "Domestic Space Research" has been the early prototyping of a format for an electronic diary. It is developed ${ }^{14}$ as a browsable HyperCard Stack of daily journals where the use of text and an expanded library of semantic icons, i.e. pictorial characters, modern hieroglyphs of typicalities, can quickly be time-indexed and retrieved.(Figure 1)

The electronic diary medium is a tool for flexible synchronic and diachronic handling of a personal or shared information-ecology: the "FÆNOLOG " software with the "IKONER" font.(Figure 2).

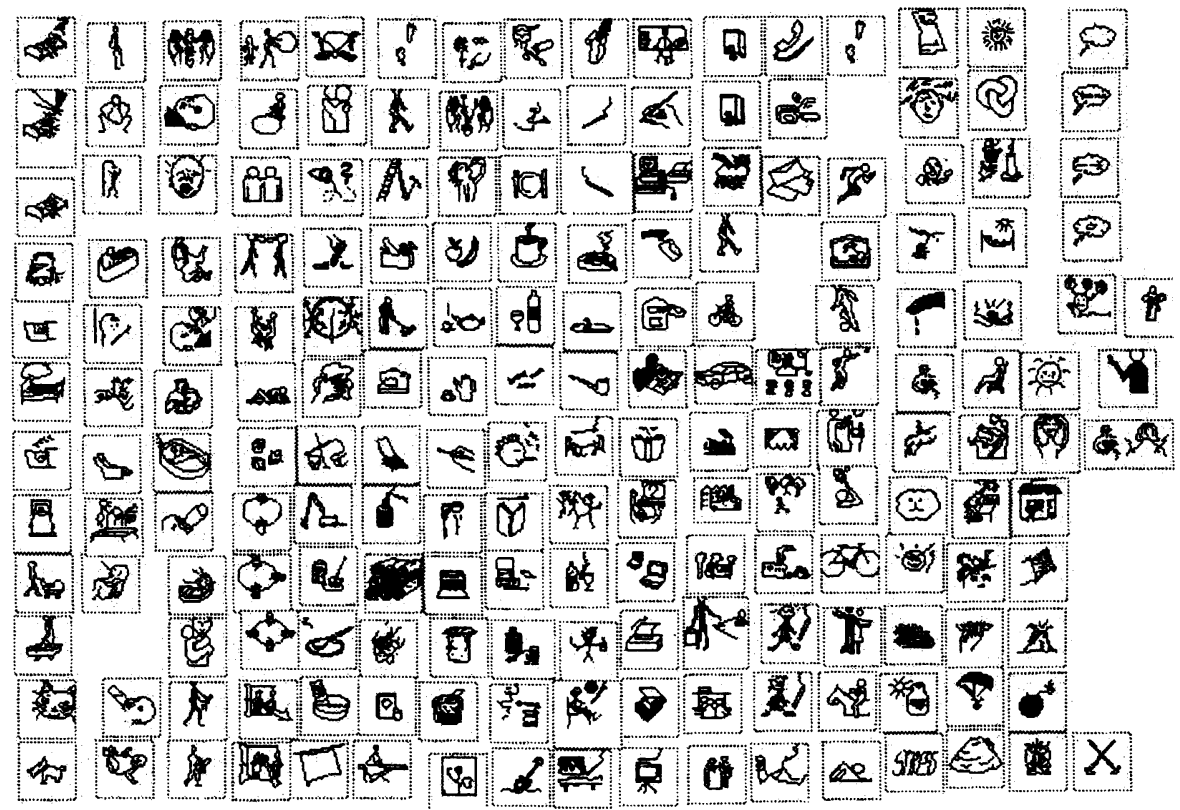

Figure 2. The types of (indefinitely size-variable) (and hopefully soon also colour-variable) icons which have emerged from my own personal needs

We are trying to build into this medium ways to cross the bridges between the parallel representational universes of Oikosphere, Somasphere and Chronosphere, through the use of user-designed icons of typicality, allowing temporal depth-perspectives to unfold, when the adequate linkable and annotable 3-D Chronospheric media and Unicode standard-font-editors become available..$^{15}$

14 with the help of Bjørn Nake and Steen Andersen

15 The icons are in the form of vectorized characters in an ASCII font. The limitation to 221 characters will be broken, as the new global Unicode standard (with room for 137,468 


\section{CONCLUSION}

It is my conclusion, that when a reversal of perspectives in this way can turn the tables, it implies, that we must put our bet on an updated version of the critical consumer, consider the home as the ultimate prototype (mother) of all civilised inhabited information-spaces, and seriously consider its potential as "investigation room" and as a platform for inhabitants' autonomous citizen science based on empowerment of self-accountability from their own local and biographic cultural soil and context.

The domestic information ecology constitutes the proto-platform for personal expression and reflection and who can deny that homes are the nuclear cells of connected community?

With this in mind, we may safely zoom out to a consideration of neighbourhoods as semi-public connected community, and the open-minded construction of the autonomous multimedia and broadband home-to-home link as the principle task of democratic ICT-policies in this decade.

\section{SELECTED THEMES FOR FURTHER DISCUSSION}

- The threat of horizontal exchange as opposed to the controllable vertical flow

- Home-link and privileged virtual home-circles

- Virtual neighbourhood

- The concept of self-accountability

- The critical consumer and long-term consumer-interests

- The health-political relevance of domestic virtual body, autonomous citizen logging and distributed domestic body and climate sensors.

- Citizens as researchers and homes as studies, studios and laboratories

- Multi-ethnicity and shareware tools for distributing and moving egoavatars and icons of event-typicality in familiar, veridical, cultural 3D virtual home-environments

- Domestic printable cartoon as everyday narrative medium

- Tools for private editing of extended Unicode standard fonts

private use characters) is spreading. A shareable Open Source Unicode standard editor is the missing link to an optimally adaptable logging tool. 


\section{REFERENCES}

[1] Altman, I. and Werner, C.M. (1985), Home Environments. Plenum Press, N.Y.

[2] Bachelard, Gaston (1957), La poetique de l'espace. PUF, Paris.

[3] Barker, Roger (1968), Ecological Psychology, Concepts and methods for studying the environment of behavior. Stanford Univ. Press, CA.

[4] Berger, Peter L. and Kellner, Hansfried (1970) Marriage and the construction of reality in; Dreitzel,Hans Peter (Ed.) Patterns of Communicative behaviour Recent Sociology no.2, MacMillan.

[5] Bjerg, K (1978), The hollow men and the public speech-act in: Jacob Mey (Ed.): Studies in Pragmalinguistics. Ser.Janua Linguarum,85 Mouton, Haag.

[6] Bjerg, K (1987), Full-scale in another sense in: (Ed.) Peder Duelund Mortensen : Proceedings of the 1st European Full Scale Workshop Conference. Boliglaboratoriets Forlag, Kbhvn.

[7] Bjerg, K. (1988). Impact of Home Interactive Telematics on the Household, - a working group report in: F. van Rijn \& R. Williams (Eds.): Concerning Home Telematics Elsevier Science Publishers, North Holland, Amsterdam

[8] Bjerg, K (1996). Home-oriented Informatics, Telematics \& Automation, in :(Eds.) Kent, A. and Williams, J.G. Encyclopedia of computer science and technology, Dekker, N.Y.

[9] Bjerg, K. (1992-2000). Principia Domestica. In Danish. >WWW.psl.ku.dk/ oikos/ OPUS/Principiaindex.htm<

[10] Bjerg, K and Borreby, K (Eds.) (1994). HOIT 94 . Prodeedings of International crossdisciplinary conference on Home-oriented Informatics, Telematics \& Automation. Univ. of Copenhagen.

[11] Boxer, Philip J. (1980). Supporting reflective learning - toward a reflexive theory of form, Human Relations, vol.33,1.

[12] Cole, M. et al. (Eds.)(1978). L.S. Vygotsky: Mind in Society. Cambridge, Mass.

[13] Csikszentmihaly, Mihaly \& Rochberg-Halton, Eugene (1981). The meaning of things: Domestic symbols and the self. Cambridge Univ.Press.

[14] Dreyfus, Hubert L. and Dreyfus Stuart E. (1986). Mind over Machine. The power of human intuition and expertise in the era of computers. Basil Blackwell.

[15] Dreyfus, Hubert L. (1991). Being-in-the-World. A commentary on Heideggers' Being and Time, Division 1, MIT Press, Cambridge, Mass.

[16] Engelsted, Niels (1994). Værdi, Verden og Virksomhedsteori, in: Sabroe, K.E., Kristensen, H. and Hegnsvad, C. (Eds.): Psykologi $i$ et jubiloeumsperspektiv. PIAU, Aarhus.

[17] Epstein, W (1993). The representational framework in perceptual theory. Perception \& Psychophysics, 56, 704-709.

[18] Fodor, J.A. and Pylyshyn, Z.W. (1981). How direct is visual perception? Some reflections on Gibson's "ecological approach". Cognition, 9, 139-196.

[19] Fodor, J.A.(1992). A Theory of Content and other essays. Cambridge, Mass.

[20] Garfinkel, Harold (1967). Studies in ethnomethodology. Prentice Hall, Englewood Cliffs, New Jersey.

[21] Gibson, J.J. (1979). The ecological approach to visual perception. L. Erlbaum Associates, Hillsdale, N.J.

[22] Goodman, Nelson (1978) Ways of Worldmaking. Hackett, Indianapolis.

[23] Giddens, Anthony (1991). Modernity and Self-identity. Blackwell, Oxford. 
[24] Heidegger, Martin (1971) Building, Dwelling, Thinking in: Martin Heideggers' Poetry, Language \&Thought. Harper \& Row N.Y

[25] Heim, Michael (1993). The metaphysics of virtual reality. Oxford Univ. Press.

[26] Heim, Michael (1998). Virtual Realism. Oxford Univ. Press.

[27] Johnson, Mark (1987). The Body in the Mind. University of Chicago Press, Ill.

[28] Kadar, E. and Effken, J. (1994). Heideggerian meditations on an alternative ontology for ecological psychology. Ecological Psychology, 6, 297-341.

[29] Kantor, David and Lehr, William (1975). Inside the Family . Jossey-Bass London.

[30] Kelly, George A. (1955) The Psychology of personal constructs. Norton, N.Y.

[31] Krippendorf, Klaus (1989) On the Ethics of Constructing Communication in: Dervin, B et. al (Eds.): Rethinking Communication, Vol.1: Paradigm Issues. Sage Pub. London.

[32] Lakoff, G. (1987). Women, Fire and Dangerous Things. What categories reveal about the mind. Chicago, Ill.

[33] Lenntorp Bo (1976). The Time geographical approach : Paths in space-time environment Lund Studies in Geography, Ser. B. Human Geog.44

[34] Leontiev, A.N. (1978). Activity, Consciousness and Personality. Englewood Cliffs, N.J.

[35] Levi-Strauss, Claude (1962). La Pensée sauvage. Plon. Paris.

[36] Lorentz, Roderique (1985). A more human history of homes in: Altman, I., Werner, C.M. Home Environments. Plenum Press, N.Y.

[37] Mace, W.M. (1977). Gibsons strategy for perceiving: 'Ask not, what's inside your head, but what your head's inside of' in Shaw, R.E. \& Bransford, J (Eds.): Perceiving, acting and knowing. Erlbaum Associates, Hillsdale, N.J.

[38] Mammen, Jens (1989). The relationship between subject and object from the perspective of Activity Theory in N.Engelsted, L Hem \& J. Mammen (eds.) Essays in General Psychology. Seven Danish contributions. Århus: Århus University Press p 71-94.

[39] Mammen, Jens (1993) The Elements of Psychology in Engelsted, N., Hedegaard, M, Karpatschof,B. and Mortensen, A. (Eds.): The Societal Subject. Aarhus University Press, Århus.

[40] Merleau-Ponty, M. (1962). Phenomenology of Perception. (Translated from Phenomenologie de la perception, Paris 1945) London

[41] Meyrowitz, J. (1985) No Sense of Place. The Impact of Electronic Media on Social Behaviour. Oxford Unversity Press.

[42] Miles, Ian (1988). Home Informatics. Information Technology and the Transformation of Everyday Life . Pinter Publishers, London.

[43] Miles, Ian., Rush, H, Turner, K. and John Bessant (1988). Information Horizons - The Long-Term Social Implications of New Information Technologies . Edward Elgar, Hampshire.

[44] Neisser, Ulric (1976). Cognition and Reality. San Francisco, Ca.

[45] Neisser, Ulric (1994). Self-perception and Self-knowledge. Psyke \& Logos, 15, 392-407.

[46] Nowotny, Helga (2000). Transgressive Competence: The Narrative of Expertise. European Journal of Social Theory, 3,1, 5-21.

[47] Nørve, Siri (1990). The home - materialized identity and household technology University of Oslo.

[48] Putnam, Hilary (1988). Representation and Reality. MIT Press, Cambridge, Mass.

[49] Schutz, Alfred (1974). The Structures of the Life World . Heinemann, London.

[50] Shum, Simon Buckingham (1996). Design argumentation as design rationale in : Kent, A. and Williams, J.G. (Eds.) Encyclopedia of computer science and technology. Dekker, N.Y. 
[51] Silverstone, Roger, David Morley, Andrea Dahlberg and Sonja Livingstone (1989). Families, Technologies and Consumption: The household and informations and communication technologies. CRICT Center for research into innovation, culture and technology. Brunel The university of West London.

[52] Slack, Jeniffer Daryll (1989) Contextualizing Technology in : Dervin, B et. al (Eds.): Rethinking Communication. Sage Pub. London.

[53] Sloane A (1994). Homelink and cyberspace in the home. Internet World International Conference, London, May 10-12, 1994.

[54] Sloane A (1996). Multimedia Communication, McGraw-Hill, London.

[55] Strauss, A \& Corbin, J (1990) Basics of Qualitative Research, Sage.

[56] Turkle, Sherry (1984). The Second Self. Computers and the human spirit Simon and Schuster, N.Y.

[57] Turkle, Sherry (1996). Life on the Screen - Identity in the age of the internet. Weidenfeld \& Nicolson, London.

[58] Vygotsky, L.S, (1927). Die Krise der Psychologie in ihrer historische Bedeutung in: Ausgewahlte Schriften 1. Köln 1985

[59] Wertsch , James W. (1995).Voices of the Mind - a sociocultural approach to mediated action. Harvard Univ. Press, Cambridge, Mass.

[60] Winograd, T. (1995). Heidegger and the design of computer systems in: Feenberg, A \& Hannay, A.(Eds.): Technology and the politics of knowledge. Indiana Univ. Press, Bloomington, Indiana.

[61] Zahoric, P \& Jennison, R.L. (1998). Presence as Being-in-the World. Presence, 7, 1. 